\title{
Annual fees: survival or cash grab?
}

$\mathrm{F}$ or patients, they seem nothing short of an up-front tax or cash grab by physicians. Many Canadians believe them to be anathema to cherished principles about health care but fear that failure to agree to the payment will result in their being struck from their family physician's roster.

They've spawned a fleet of firms whose primary mission appears to be to act as a de facto collection agency for physicians, typically pocketing a crisp $15 \%$ for each patient who ponies up the cash.

Doctors, though, counter that one of the fastest growing crazes in family medicine - charging each patient an annual fee on the order of $\$ 50$ to $\$ 300$ for uninsured services - is actually necessary to their financial survival, and results in costs savings for their patients.

No hard and fast numbers are kept by medical associations, professional colleges or governments regarding the number of doctors who are now collecting annual fees in Canada. The College of Family Physicians and Surgeons of Canada, for example, has "no idea" how many doctors across the country are now collecting annual fees.

But the growing number of private firms that collect yearly fees for uninsured services on behalf of doctors suggests that the practice is on the rise.

The fees are legal in all provinces but Quebec, which prohibits all doctors who bill the public system for services from charging patients annual fees. Still, many do, as evidenced by recent controversy in the media, says Marc Lortie, spokesman for the Regie de l'Assurance Maladie du Quebec.

In all other provinces, family physicians can charge the fee for uninsured services so long as patients are given the option to pay separately for uninsured services as needed.

There are now at least four companies specializing in helping doctors collect annual fees from patients in Canada and it's clearly a growth industry.

Adam Hutton, vice president of prod-

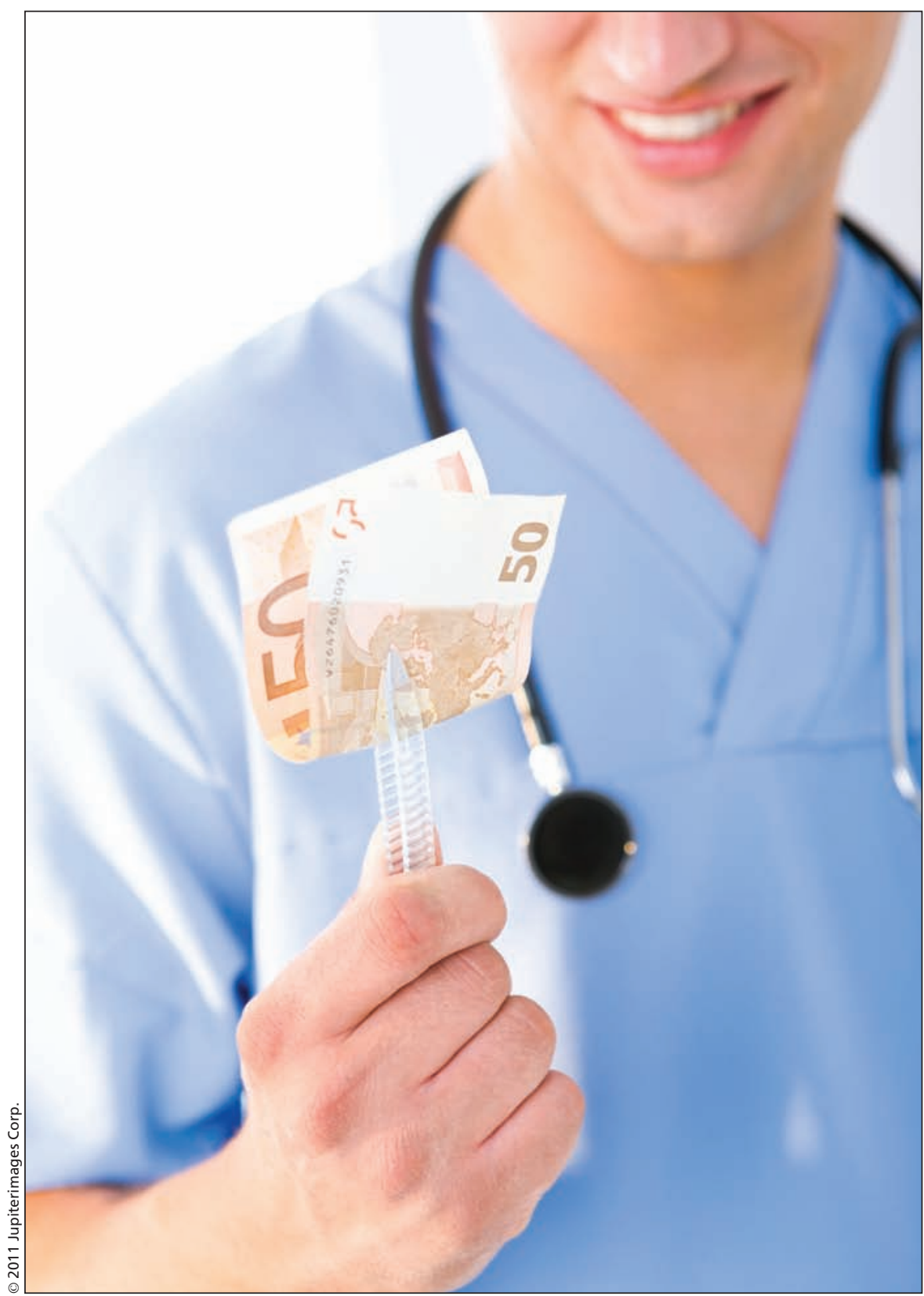

Critics of annual fees charged by doctors say that patients feel compelled to pay them, for fear they'll lose the services of their family physician.

uct management for Healthscreen, the largest player in the business, says "a couple of our competitors just launched in the past couple of years." Healthscreen has grown continuously since it first began offering fee collection services in 2003, he says, while refusing to disclose the size of the firm's client base. The company was quoted in 2009 , however, as representing 3000 physicians.

Physicians argue that the fees are justified because provincial health plans don't pay for many services doctors provide. They also argue that it's a win-win situation: patients get a discount by paying an annual fee, rather 
than paying individually for each service, while doctors don't have to chase patients for money each time they provide an uninsured service.

The precise services that are covered by an annual fee vary significantly from doctor to doctor, but often include telephone renewal of prescriptions, extra physicals for camp or school admissions, sick notes, phoned-in prescriptions and the fee for missed appointments.

Critics charge that the annual fees are a cash grab.

"In some cases, it's going far beyond the ostensible reason doctors need to charge fees and it's about a separate income," says Natalie Mehra, director of the Ontario Health Coalition.

Patients feel compelled to pay them, to ensure that they continue to have the services of a physician, Mehra adds. "Patients think: 'If I don't pay this, am I going to lose my family doctor?' Or: 'Am I going to be dropped to the bottom of the list'?"

The situation is even murkier with regard to the fees charged by private clinics, Mehra says, asserting that such facilities are using annual fees to "sell elite access to a family physician" and rack up profits. That notion is supported by recent events in Quebec, which saw the province's health insurer, Regie de l'Assurance Maladie du Quebec announce that it was investigating 11 private clinics that were billing patients anywhere from $\$ 400$ to $\$ 1500$ for uninsured services.

"It's impossible to get a [family] physician in Montreal unless you're very rich and Montreal probably has the most 'boutique clinics' in the country," Mehra says.

But doctors say that while there may be abuses in the form of physicians who charge exorbitant fees, or pressure on patients into anteing up, most are playing by the rules.

In fact, doctors charge annual fees not to make big profits, but simply to get remunerated for the work they do, says Dr. Benjamin Burko, a pediatrician in Montreal."It's well known that there are services that patients demand that are not covered by provincial medicare plans, including telephone advice and communicating and discussing lab results," says Burko.

He says the fees also make sense for patients who often require uninsured services for convenience's sake. "If you need a prescription renewed for a chronic condition and you can pay $\$ 30$ to $\$ 35$ for a physician to phone it in, or sacrifice half a day of work to get an appointment, it's almost a no-brainer," he says.

By charging a one-time fee annually "the patients get a discount and it saves administration costs for the physician," Burko explains. Fundamentally, however, the trend in annual fees speaks to the larger issue of how provincial insurers pay physicians, argues Burko. "More than 15 to $20 \%$ of a physician's work day is for services of which they get a grand total of zero." - Wendy Glauser, Toronto, Ont.

CMAJ 2011. DOI:10.1503/cmaj.109-3815

\section{Federal budget becomes election plank}

$\longrightarrow$ ritics and skeptics called it small and unimaginative. Opposition parties immediately indicated that they would blow it out of the Parliamentary waters and plunge Canadians into a general election. The government, though, called it "leadership."

"Our plan does not say 'yes' to every demand; it does not contain massive new spending — because that's not leadership,” Finance Minister Jim Flaherty said on Mar. 22 while unveiling the government's fiscal blueprint for 2011-12. "Leadership is about finding a balance between needs."

It should also be about vision, says Canadian Medical Association President Dr. Jeff Turnbull.

"Canadians expected to see significant changes to health care in this budget," he says. "We had hoped that we would see things like pharmacare and long-term care and national standards and accountability systems as we move towards 2014," when the current financ- ing agreement on health transfers to the provinces expires.

"Yes, there are a lot of small initiatives that impact on health, each one a good start in a direction but it has to be into a framework, an over-arching transformed health care system that serves Canadians."

Among the modest, health-related measures in the budget was a scheme to attract doctors, nurses and nurse practitioners to "under-served rural and remote" communities by forgiving a portion of their Canada Student Loans if they set up a shingle in isolated environments, commencing in fiscal 2012-13.

But exactly what constitutes such communities remains to be determined, Finance officials said, on condition of anonymity, during a background briefing on the blueprint. "Some people use population. Others use proximity to health centres. We'll have to establish a proper national standard."

Finance officials say that roughly 900 doctors and 1600 nurses graduate annu- ally in debt to the Canada Student Loans program. It's estimated the average medical student graduates with a debt load on the order of $\$ 100000$. They'll be eligible to have $\$ 8000$ per year written off their loans, to a maximum $\$ 40000$, while nurses and nurse practitioners will be eligible for a $\$ 4000$ per year write-off, to a maximum $\$ 20000$, if they undertake a stint in a remote community.

The government also allocated roughly $\$ 40$ million in 2011-12 for a non-refundable family caregiver tax credit to those providing care to infirm or dependent relatives, including spouses, common-law partners and children.

Essentially, those caring for loved ones meeting certain criteria will get a tax credit of $\$ 2000$. But as with existing health-related tax support, it will be reduced by $15 \%$ for every dollar earned (including pensions) by the person receiving care, and essentially disappear at an income level of \$21360.

In a related measure, the government eliminated the $\$ 10000$ ceiling for 